\title{
ANALISIS KUALITAS INTENSITAS LASER ATOM TERKOPEL LEMAH
}

\author{
T. B. Prayitno*1 dan Iwan Sugihartono*2
}

\author{
*Universitas Negeri Jakarta, Jl. Pemuda Rawamangun No. 10
}

1teguh-budi@unj.ac.id, 2isugihar@hotmail.com

\begin{abstract}
Abstrak
Dalam makalah ini telah dikaji beberapa profil intensitas laser atom terkopel lemah untuk beberapa parameter yang didapatkan dengan menyelesaikan persamaan Schrödinger yang merepresentasikan persamaan gerak laser atom. Persamaan Schrödinger ini hasil reduksi dari persamaan Gross-Pitaevskii yang terkopel antara kondensat dan atom laser, dimana laser atom tersebut dikeluarkan dari kondensat. Pada kasus ini, kita hanya meninjau perambatan laser atom dalam arah longitudinal karena kita mengambil kasus perangkap berbentuk cerutu (cigar-shaped trap).
\end{abstract}

Keywords: intensitas, persamaan Schrödinger, laser atom.

\section{Pendahuluan}

Kajian mengenai kondensasi Bose-Einstein merupakan salah satu kajian yang menarik dalam bidang fisika energi rendah. Kondensasi ini terjadi dengan melakukan pendinginan terhadap kumpulan atom-atom, terutama atom alkali, sampai mendekati suhu 0 Kelvin atau mendekati suhu kritis dari atom-atom yang dipilih, contoh serangkaian eksperimen yang pernah dilakukan yaitu, kondensasi Bose-Einstein di dalam gas dari atom rubidium [1], sodium [2], dan litium [3]. Hal ini ditandai dengan munculnya puncak yang tajam pada distribusi momentum dan posisi yang dilihat melalui metode optik [4]. Apabila kondensasi telah terjadi, masing-masing gelombang de Broglie dari setiap atom tersebut akan saling tumpang tindih sehingga untuk kasus yang istimewa akan terciptalah satu gelombang de Broglie. Secara kuantum, kita dapat mengatakan bahwa sebagian besar atom-atom tersebut berada pada tingkat energi terendah yang dikelilingi oleh awan gas hasil dari kondensasi yang dikenal sebagai kondensat.

Percobaan kondensasi Bose-Einstein biasanya dilakukan dengan membuat suatu perangkap magnetik untuk mengurung atom-atom tersebut [5]. Secara kuantum, kita dapat mengatakan bahwa atom-atom tersebut dalam kondisi terperangkap. Untuk membuat atom-atom tersebut bebas dari perangkap tersbut, maka dibutuhkan suatu gelombang elektromagnetik yang ditembakkan ke kumpulan atom-atom tersebut, dimana atom tersebut akan menggunakan energi yang ditangkap dari gelombang elektromagnetik itu untuk keluar. Cara inilah yang nantinya digunakan untuk menghasilkan suatu laser atom. Laser atom dapat dihasilkan dengan membebaskan atom-atom tersebut secara kuantum dengan menembakkan gelombang elektromagnetik pada kumpulan atom yang dikelilingi oleh kondensat. Dengan kata lain, laser atom dihasilkan dengan mengekstrak atom dari kondensat [6-12].

Menurut hasil percobaan, laser atom merupakan sejenis laser, namun mempunyai karakteristik yang unik yang tidak dimiliki oleh laser pada umumnya. Menurut teori kuantum laser merupakan salah satu wujud gelombang elektromagnetik yang mempunyai massa nol sebagai akibat adanya tafsiran teori relativitas khusus. Namun demikian, hal di atas tidak berlaku atom laser atom karena pada dasarnya laser atom tercipta dari atom yang terekstrak dari kondensat. Dengan demikian, laser atom mempunyai massa yang signifikan sehingga pergerakan dari laser atom tersebut akan dipengaruhi oleh gravitasi bumi [13]. Pengaruh dari gravitasi bumi itu akan mempercepat pergerakan laser atom tersebut sehingga gelombang de Broglie dari laser atom tersebut akan terus menerus. Hal ini menyebabkan kualitas dari laser atom tersebut menurun karena intensitas laser atom tersebut berbanding lurus dengan rapat probabilitas yang dihasilkan. Dengan demikian, kita memerlukan potensial tambahan untuk mengatasi percepatan gravitasi bumi tersebut.

Upaya untuk mencari intensitas laser atom umumnya sangat sulit dilakukan karena persamaan yang mendeskripsikan pergeraan laser atom merupakan persamaan Gross-Pitaevskii yang nonlinear dan terkopel dengan persamaan Gross-Pitaevskii yang mendeskripsikan gerak kondensat. Namun demikian, apabila kita menganggap bahwa gas boson yang dihasilkan bersifat cair, maka persamaan Gross-Pitaevskii yang terkopel tersebut akan dapat dipisahkan satu sama lain menjadi persamaan Schrodinger [14]. Istilah cair dalam kasus ini berarti bahwa jarak interaksi antar atom jauh lebih kecil dibandingkan jarak atom satu sama lain. Kedua persamaan tersebut adalah persamaan Schrodinger non 
homogen yang mendeskripsikan persamaan gerak laser atom dan persamaan Schrodinger homogen yang mendeskripsikan gerak kondensat.

Pada makalah ini kita akan menampilkan beberapa intensitas laser atom untuk beberapa kasus, yaitu dengan mengubah parameterparameter yang terkait. Hal ini diharapkan sebagai pembanding untuk dapat mengkaji seberapa besar pengaruh percepatan gravitasi tersebut. Pada sesi berikutnya kita akan membahas bentuk matematis yang terkait dengan gerak kondensat dan laser atom dan cara menyelesaikan persamaan berikut. Hasil dari komputasi persamaan gerak tersebut untuk beberapa kasus akan diberikan pada sesi hasil dan pembahasan. Rangkuman dari semua hasil pembahasan akan diberikan dalam sesi kesimpulan.

\section{Metode}

Pada bagian ini akan dikaji ulang beberapa persamaan yang terkait dengan persamaan laser atom yang terkopel lemah. Persamaan laser atom yang terkopel lemah yang berada di dalam dan di luar daerah kondensat berturut-turut diberikan oleh dua persamaan berikut [13-15]

$$
i \hbar \frac{\partial \psi_{\ell}}{\partial t}=\left(-\frac{\hbar^{2}}{2 m} \nabla^{2}+V_{\ell}+g_{c \ell}\left|\psi_{c}\right|^{2}\right) \psi_{\ell}+\chi
$$

$$
i \hbar \frac{\partial \psi_{\ell}}{\partial t}=\left(-\frac{\hbar^{2}}{2 m} \nabla^{2}+V_{\ell}+g_{c \ell}\left|\psi_{c}\right|^{2}\right) \psi_{\ell}
$$

dengan $\psi_{\ell}$ adalah fungsi gelombang laser atom sedangkan $\psi_{c}$ merupakan persamaan gerak kondensat yang memenuhi persamaan gerak [14, 15]

$$
i \hbar \frac{\partial \psi_{c}}{\partial t}=\left(-\frac{\hbar^{2}}{2 m} \nabla^{2}+V_{c}+g_{c c}\left|\psi_{c}\right|^{2}\right) \psi_{c}
$$

Selain itu, pada kasus ini potensial eksternal yang diterapkan pada laser atom di dalam dan di luar daerah kondensat memenuhi hubungan $[14,15]$

$$
\begin{aligned}
V_{\ell}(\vec{r})= & -\mu+\frac{1}{2} m\left[\omega_{\perp}^{2}\left(x^{2}+y^{2}\right)+\omega_{z}^{2} z^{2}\right] \\
& +\frac{1}{2} m \omega_{\perp}^{2} \sigma^{2} \\
V_{\ell}(\vec{r})= & -\frac{1}{2} m \omega^{2} \sigma_{q}{ }^{2}+\frac{1}{2} m \omega^{2}\left[x^{2}+\left(y+\sigma_{q}\right)^{2}\right]
\end{aligned}
$$

dengan $\sigma=g / \omega_{\perp}^{2}$ dan $\sigma_{q}=g / \omega^{2}$ merupakan kuantitas pergeseran yang dialami oleh laser atom akibat adanya medan gravitasi bumi yang berarah pada sumbu-y.

Untuk mencari profil dari solusi gelombang laser atom, kita harus terlebih dahulu mencari solusi fungsi gelombang kondensat. Dengan menerapkan perangkap berbentuk cerutu

$$
V_{c}(\vec{r})=\frac{1}{2} m \omega^{2}\left(x^{2}+y^{2}+\lambda_{z}^{2} z^{2}\right)
$$

dengan $\lambda_{z} \equiv \omega_{z} / \omega_{\perp}<<1$, solusi gelombang stabil dapat diperoleh dengan menggunakan koordinat silinder

$$
\begin{aligned}
\psi_{c}(\rho, z, t)= & \sqrt{\frac{N}{a_{0}^{3}}} \lambda_{z}^{1 / 8} \pi^{-3 / 4} \exp \left(-\rho^{2} / 2-z^{2} / 2\right) \\
& \exp \left(i\left[\kappa+\omega_{\rho}\right] t\right)
\end{aligned}
$$

Untuk mencari solusi fungsi gelombnag laser atom dalam daerah kondensat, kita melakukan transformasi berikut ini [15-16]

$$
\begin{gathered}
\psi_{\ell} \rightarrow \psi_{\ell} / \sqrt{\hbar \omega_{\perp} / 2 \sqrt{\lambda_{z}}} \\
t \rightarrow t / 2 \omega_{z} \\
(x, y, z) \rightarrow(x, y, z) / a_{0}
\end{gathered}
$$

Dalam hal ini kita mendefinisikan $\omega_{z}$ sebagai frekuensi dalam arah longitudinal, $\omega_{\perp}$ sebagai frekuensi dalam arah radial, $a_{0}$ adalah panjang osilator harmonik. Pada makalah kami yang terakhir, dengan melakukan transformasi yang dinyatakan dalam koordinat silinder

$$
\begin{gathered}
\psi_{\ell}=\alpha(\rho) \beta(z) e^{-i \gamma t} \\
\chi=\alpha(\rho) \phi(z) e^{-i \gamma t}
\end{gathered}
$$

kita akan mendapatkan persamaan differensial tak bermassa dalam arah longitudinal yang berbentuk persamaan

$$
\frac{d^{2} \beta}{d z^{2}}-z^{2} \beta-g_{c \ell}\left|\psi_{c}\right|^{2} \beta+\Omega \beta=-\phi
$$

dengan definisi $\Omega=\frac{1}{2} m \omega_{\perp}^{2} \sigma^{2} / \sqrt{\lambda_{z}}-\mu / \sqrt{\lambda_{z}}$.

Pada kasus persamaan laser atom yang berada di luar daerah kondensat kita hanya dapat bekerja pada koordinat kartesis mengingat metode separasi variabel tidak dapat dilakukan dalam koordinat silinder. Oleh sebab itu, dengan menerapkan transformasi dalam koordinat kartesis berikut

$$
\begin{gathered}
\psi_{\ell}=X(x) Y(y) Z(z) e^{-i E t} \\
t \rightarrow t / 2 \omega_{z} \\
(x, y, z) \rightarrow(x, y, z) / a_{0}
\end{gathered}
$$


Kita akan mendapatkan persamaan gelombang dalam arah longitudinal berikut

$$
\frac{d^{2} Z}{d z^{2}}+\alpha \frac{\sqrt{2}}{2} \lambda_{z}^{\frac{1}{4}} \pi^{-\frac{3}{2}} z^{2} Z=-\left(E_{z}-\alpha \frac{\sqrt{2}}{2} \lambda_{z}^{\frac{1}{4}} \pi^{-\frac{3}{2}}\right) Z
$$

dengan definisi $\alpha=2 g_{c \ell} / \hbar \omega \sqrt{\lambda_{z}}$.

\section{Hasil dan Pembahasan}

Dari persamaan differensial pada persamaan (13) dan (17), kita akan menurunkan solusi analitik atau pun numerik. Persamaan (13) tidak mempunyai solusi analitik karena keberadaan suku non homogen di sisi kanannya sehingga kita hanya bisa mendapatkan solusi numerik. Dengan mensubstitusikan fungsi $\psi_{c}$ pada persamaan (7) ke persamaan (13), lalu diikuti dengan mengintegrasikan kedua ruas persamaan (13) terhadap seluruh ruang, kemudian kita menerapkan kondisi $e^{-2 z^{2}} \approx 1-2 z^{2}$, kita akan mendapatkan persamaan differensial yang merupakan persamaan gerak laser atom dalam arah longitudinal

$$
\frac{d^{2} \beta}{d z^{2}}+\left(2 g_{c \ell}-1\right) z^{2} \beta+\left(\Omega-g_{c \ell}\right) \beta=-\phi
$$

Berikut ini beberapa profil rapat probabilitas dari fungsi gelombang laser atom untuk beberapa nilai $\Omega$ dan $\phi$ [15].

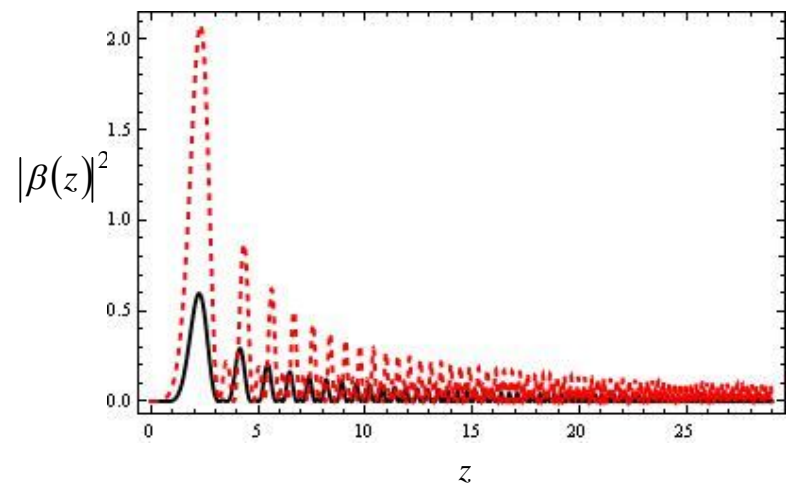

Gambar 1. Grafik $|\beta(z)|^{2}$ terhadap koordinat z untuk kondisi $\phi=z$

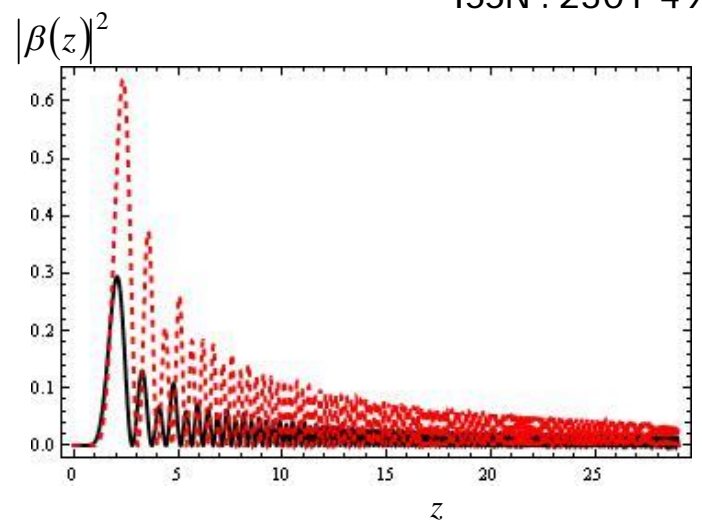

Gambar 2. Grafik $|\beta(z)|^{2}$ terhadap koordinat z untuk kondisi $\phi=\sin z$

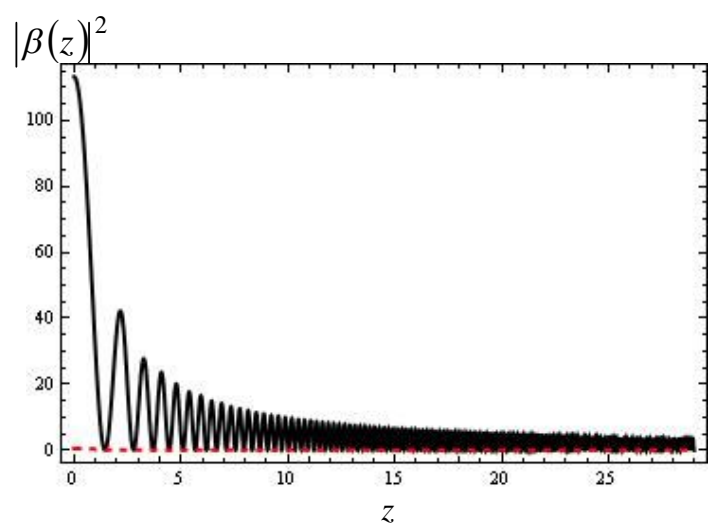

Gambar 3. Grafik $|\beta(z)|^{2}$ terhadap koordinat z untuk kondisi $\phi=\cos z$

Pada kasus ini, kita telah membedakan paramater $\Omega$ dengan kondisi

--------- menunjukkan $\Omega=0$

menunjukkan $\Omega=2$

Untuk persamaan gelombang laser atom di luar daerah kondensat hanya nilai $\alpha$ negatif yang dapat memberikan solusi, yaitu solusi analitik. Solusi analitik tersebut dinyatakan dalam fungsi Hermit yang dapat dituliskan

$$
Z_{n}(z)=\sqrt{\frac{1}{2^{n} n ! \sqrt{\pi}}} \xi^{1 / 8} e^{-\sqrt{\xi} z^{2} / 2} H_{n}\left((\sqrt{\xi})^{1 / 2} z\right)
$$

dimana kita telah mendefinisikan hubungan $\xi=\alpha \frac{\sqrt{2}}{2} \lambda_{z}^{1 / 4} \pi^{-3 / 2}$ dan $H_{n}$ adalah polinomial Hermit. Berikut ini adalah beberapa profil rapat probabilitas dari fungsi laser atom terhadap koordinat z 


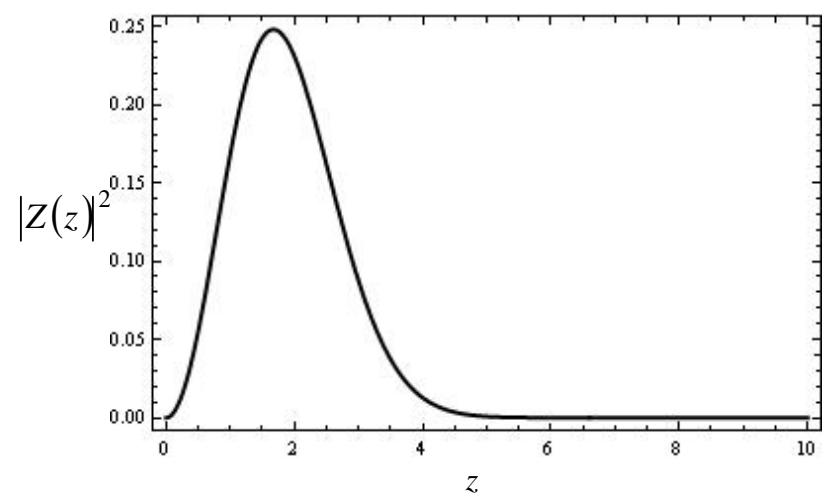

Gambar 4. Grafik $|Z(z)|^{2}$ terhadap koordinat z untuk kondisi $n=1$

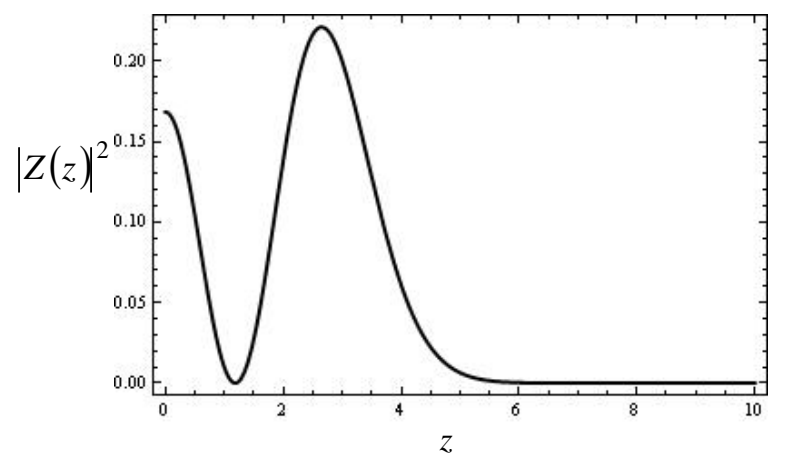

Gambar 5. Grafik $|Z(z)|^{2}$ terhadap koordinat z untuk kondisi $n=2$

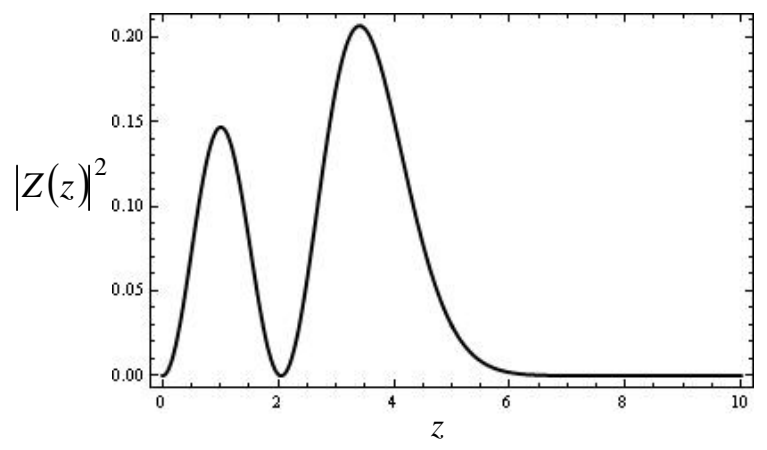

Gambar 6. Grafik $|Z(z)|^{2}$ terhadap koordinat z untuk kondisi $n=3$

\section{Kesimpulan}

Di dalam makalah ini telah diturunkan solusi analitik dan numerik untuk persamaan gerak laser atom terkopel lemah di luar dan di dalam daerah kondensat dengan melakukan terlebih dahulu metode separasi variabel. Untuk laser atom yang berada di dalam daerah kondensat, kita hanya dapat mencari solusi numerik karena adanya keberadaan suku non homogen sedangkan solusi analitik untuk laser atom yang berada di luar daerah kondensat hanya dapat diperoleh untuk nilai $\alpha$ negatif. Kita melihat dari gambar 1 dan 2 bahwa rapat probabilitas dari laser atom pada $\Omega=2$ lebih tinggi dari $\Omega=0$, sedangkan rapat probabilitas dari laser atom pada $\Omega=0$ lebih tinggi dari $\Omega=2$ seperti yang ditunjukkan pada gambar meskipun semua profil yang terlihat dari gambar 1-3 terlihat bahwa profil osilasi mirip seperti osilasi teredam. Dengan demikian, kita dapat menyimpulkan secara kualitatif bahwa intensitas dari laser atom akan tereduksi dengan cepat akibat dari adanya faktor redaman.

Untuk kasus selanjutnya, yaitu gelombang laser atom di luar daerah kondensat, kita melihat bahwa semua profil rapat probabilitas bergantung kepada indeks diskrit $\mathrm{n}$ yang hanya berlaku untuk $\alpha$ negatif. Di samping itu, untuk $z \rightarrow \infty$, semua profil akan menuju ke nilai nol meskipun profil osilasi masih dapat dilihat. Namun demikian, osilasi pada daerah ini tidak secepat pada profil rapat densitas gelombang laser di dalam daerah kondensat.

\section{Ucapan Terima Kasih}

Penelitian ini dibiayai oleh dana PNBP-BLU Fakultas Matematika dan Ilmu Pengetahuan Alam Universitas Negeri Jakarta tahun anggaran 2015 dengan nomor kontrak No. 36/ SPK Penelitian/ 6.FMIPA/ 2015.

\section{References}

[1] M.H. Anderson, J.R. Ensher, M.R. Matthews, C.E. Wieman, E.A. Cornell, Science 269 (1995) 198.

[2] K.B. Davis, M.O. Mewes, M.R. Andrews, N.J. van Druten, D.S. Durfee, D.M. Kurn, W. Ketterle, Phys. Rev. Lett. 75 (1995) 3969.

[3] C.C. Bradley, C.A. Sackett, J.J. Tollett, and R.G. Hulet, Phys. Rev. Lett. 75 (1995) 1687.

[4] F. Dalfovo, S. Giorgini, L.P. Pitaevskii, S. Stringari, Rev. Mod. Phys. 71 (1999) 463.

[5] Y. S. Kivshar, T. J. Alexander, and S. K. Turitsyn, Phys. Lett. A 278 (2001) 225.

[6] I. Bloch, T. W. Hänsch, T. Esslinger, Phys. Rev. Lett. 82 (1999) 3008, arXiv: condmat/ 9812258

[7] J. Schneider, A. Schenzle, Appl. Phys. B. 69 (1999) 353. 
[8] F. Gerbier, P. Bouyer and A. Aspect, Phys. Rev. Lett. 86 (2001) 4729.

[9] Th. Busch, M. Köhl, T. Esslinger, and K. Mølmer, Phys. Rev. A 65 (2002) 043615.

[10] G. Cennini, G. Ritt, C. Geckeler, and M. Weitz, Phys Rev. Lett. 91(2003) 240408.

[11] A. J. Leggett, Rev. Mod. Phys. 73 (2001) 307.

[12] J.-F. Riou, W. Guerin, Y. Le Coq, M. Fauquemberque, V. Josse, P. Bouyer, A. Aspect, Phys Rev. Lett. 96 (2006) 070404, arXiv: cond-mat/ 0509281.

[13] T. B. Prayitno. Makara J. Sci. 18 (2014) 119.

[14] J.-F. Riou, Y. Le Coq, F. Impens, W. Guerin, C.J. Bordé, A. Aspect, P. Bouyer, Phys. Rev. A 77 (2008) 033630.

[15] T. B. Prayitno dan Iwan Sugihartono, Laporan Penelitian FMIPA UNJ dengan dana PNBP-BLU UNJ (2015).

[16] T. B. Prayitno, Widyanirmala, I. H. Belfaqih, T. E. K. Sutantyo, and I. M. Astra, Adv. Mat. Res. 1123 (2015) 13. 